\title{
Introduction to A Research Agenda for Creative Industries
}

\author{
Stuart Cunningham and Terry Flew
}

\section{Introduction}

The year 2018 marked the twentieth anniversary of the UK's development of the first Creative Industries Mapping Document from the Department of Culture, Media and Sport (DCMS) - which is widely recognised as having given rise to a distinctive policy paradigm that several jurisdictions across the world have embraced. It has also given rise to numerous critiques that align it with neoliberalism and the depoliticisation of culture, and that have predicted - without accuracy or success - its demise as an organising framework for policy makers, industry identity and advocacy, and research.

Its original definition - 'those industries which have their origin in individual creativity, skill and talent and which have the potential for wealth and job creation through the generation and exploitation of IP' (DCMS 1998) - has been contested, augmented and developed over this period. The concept of creative industries brought together for the first time industry sectors ranging from architecture and design, through established media sectors, to a range of new media sectors including games and software, through to the visual and performing arts. This core definitional innovation has remained largely intact across these twenty years, although the tensions it creates are also, as we will see, constitutive of debate about the creative industries.

The fundamental claims made in that initial UK intervention were that the sector was much larger than previously thought, and was growing at a much faster rate than the rest of the economy. Given that the creative industries concept was developed as a joint industry-policy initiative (by the UK government in the late 1990s), scholarly attention to and criticism of it is a function of its existence as a hybrid assemblage of industry activity, human creative endeavour, research work, state policies and programmes, and curriculum, pedagogy and training. In numerous parts of the world, a research agenda for creative industries is now inextricably tied to the concept's deployment in policy, programmes and education.

The contributors to this book - industry and policy leaders as well as scholars - broadly and non-dogmatically share a view of the creative industries idea as a productive and innovative intervention in public policy that has generated a robust 
research agenda that is worth reflecting and building on. In the spirit of the series in which this book appears - in which 'contributors are given space to explore their subject in provocative ways, and map out potential directions of travel' - we will not, in this Introduction, thoroughly map the territory, as might be conventional. You will find a number of 'introductions' to the field in the book. Chapter 1 introduces what is important about the field from the perspective of an industry and policy leader. Both Chapters 3 and 4 offer strategic overview summaries of the shape of disciplinary research in the field.

Instead, here we focus on asking three key strategic questions that are critical to shaping a research agenda for creative industries. Many of the book's contributors also address these issues from their own perspectives:

- How much should a research agenda for creative industries be shaped by a policy and industry orientation?

- Is it important to differentiate economic, cultural and social rationales for and outcomes from creative industries, or should they be converged around the so-called 'triple bottom line'?

- What research agendas can be developed from studying the embedding of creative industries approaches and concepts into education: curriculum, pedagogy, promotion and alumni tracking?

\section{How much should a research agenda for creative industries be shaped by a policy and industry orientation?}

Academic disciplinary knowledge is typically generated by the successive refining of methods of enquiry and the stabilisation of, and consensus around, objects of enquiry. Developing research agendas for creative industries could not be further from this kind of activity. Looking back at the 'birth' of creative industries, John Newbigin, in Chapter 1 , reminds us of the politically experimental, contingent nature of the 'uncharted territory' of 'raising the profile of an eclectic jumble of generally IP-based, culturally-rooted businesses that governments and banks had conspicuously failed to understand or take seriously as part of the economy'. Lutz and Karra (2009, p. 117) argued that DCMS' definition 'does not provide any systematic, persuasive or logical explanation of what precisely its clump of thirteen subsectors (advertising, architecture, art and antiques, crafts, design, designer fashion, software, film and video, music, performing arts, publishing, television and radio) share'. Emphasising these contingent beginnings is by no means to say that rigorous disciplinary knowledge cannot, or should not, be brought to bear in creative industries research. Indeed, much of this book is dedicated to the challenges creative industries pose for knowledge generation in a wide variety of disciplines. It also does not mean that there are not recurrences, consistencies and even constants that researchers can identify as distinctly constituting the field of creative industries research. These fundamental points will arise throughout this book. 
To study creative industries, then, is to study a hybrid assemblage of industry and policy phenomena which is under constant pressure for development and adaptation to economic, political and technological conditions and forces, many of which lie outside its control. And the nature of policy discourse - as one of us has argued some time ago (Cunningham 1992) - is that it is not 'ideas rich', but 'ideas thick': 'Policy discourse can appear dry, boring and opaque to the critic because it is a ritualised, procedural, highly repetitious form of public discourse and is the expression of firm hierarchies of authority which define its intelligibility' (p. 35). Its purpose is typically to represent and manage incommensurate logics and ideals just as it is usually the outcome of contending stakeholders. As an 'assemblage', it is not the outcome of independent, systematic thought. It is strategic, 'contingent articulations among myriad heterogeneous elements' (https:/en.wikipedia.org/ wiki/Assemblage_theory).

Consider, again, the original definition: 'those industries which have their origin in individual creativity, skill and talent and which have the potential for wealth and job creation through the generation and exploitation of IP'. This definition is managing the relationship between old and new media, art and commerce, traditional individualist notions of creativity and industrialised collective endeavours based on IP 'generation and exploitation'. Very succinctly, in the phrase 'wealth and job creation', it attempts to manage the notorious gap in the creative industries between the wildly successful few and the many getting by or struggling - what Richard Caves (2000) called the 'A list/B list' phenomenon. This management of the incommensurate makes policy discourse dynamic but unstable. As we will see later in this Introduction, and at various points in the book, it is open to critique that 'The creative industries don't exist - at least not as a unified category' (Davies and Sigthorsson 2013, p. 1).

We now focus on two aspects of what a research agenda oriented to policy and industry concerns opens up. The first is concerned with strategic institutional positioning of research in the context of the so-called Impact (or Engagement and Impact) agenda as it is evolving in the UK and Australia as an adjunct to research quality assessment exercises (the REF or Research Excellence Framework, and Engagement and Impact (EI) as part of Excellence in Research Australia, or ERA). Of course, as Mats Benner (2018) points out, there are few university systems worldwide that are not engaged in debates about, or deeply embedded in, engagement and impact - although it is the 'gift' of the Anglosphere, and currently and particularly UK and Australia, to wish to seek to measure it in countrywide assessment exercises conducted independently of university jurisdiction. Accompanying these exercises are urgings to build engagement and impact into the conceptualisation of research rather than to add their consideration ex post facto, and the re-drafting of research grant applications to draw attention to such urgings and give it a weighted value.

Such exercises have seen a range of case studies of academic research's engagement with creative industries. Amongst the numerous impact case studies submitted 
to the first UK REF in 2015 were, for example, 'Supporting Digital Media and the Creative Industries' (University of Ulster, https://impact.ref.ac.uk/CaseStudies/ CaseStudy.aspx?Id=1926), 'A measure for the creative economy' (King's College London, https://impact.ref.ac.uk/CaseStudies/CaseStudy.aspx?Id=41318), and 'Cultural and Creative Industry Clusters and City Growth' (London Metropolitan University, https://impact.ref.ac.uk/CaseStudies/CaseStudy.aspx?Id=20080). The first iteration of the EI in Australia in 2018 also saw Queensland University of Technology submit an impact case study on 'Creative Industries Mapping: Establishing the Significance of the Size and Scope of the Creative Economy', while the University of Newcastle submitted on 'Investigating and supporting creative industries as an entrepreneurial system'. The simple point to be made is that a research agenda oriented to policy and industry is well placed to account for its relevance and value beyond the academy.

Another practical consequence of adopting this position is that research agendas can be generated around distinct policy domains that engage the different disciplinary knowledges that underpin research in the creative industries, as well as allowing the blurring and convergence of policy domains to come into prominence. This means that the development of research agendas can at the same time lead to strategies for scholars' engagement and impact. Cultural policy is clearly the central domain impacted by creative industries - Chapters 2, 4, 8 and 9 all engage with implications arising from creative industries for cultural policy.

Creative industries are often treated as an outlier in industry policy (but see Chapter 2) and the battles over the neglect of the creative sector in STEM-centric innovation policies are set to become more important (see Cunningham 2014). It is significant that several definitions of creative industries (and a whole monograph; see Stoneman 2011) focus on innovation. For Kimpeler and Georgieff (2008), creative industries 'comprise of particularly innovative lines of businesses. . . . They play a special role as creative input providers in the innovation system' (p. 209). And for Müller et al. (2008, p. 3) they 'are not only - by definition - a source of creativity, but they also show a strong performance in technological innovation and thus directly contribute to the level of industrial innovation in the economy in terms of technologically new products, new processes and results of their own R\&D efforts'.

There is a strong argument that urban policy and planning play a more decisive role in how creative industries actually impact day-to-day life than policies that national governments typically produce (see Chapter 4). Grassroots activist Marcus Westbury (2015) has argued that municipal bureaucracy plays a more dramatic role in encouraging or inhibiting urban creative scenes than much national cultural policy. Some of the debates with greatest depth and international engagement are played out around the role of the creative sector in the amenity of cities (Florida 2002, 2017), its contribution to gentrification and affordability (Oakley and Ward 2018), and whether creative industries are an intrinsically inner-urban phenomenon, or can thrive in suburban, peri-urban, or rural environments (Flew 2012; Markusen 2014). 
Here, we make a few more detailed comments on intellectual property policy and the creative industries, while also flagging that Chapter 8 is a focused case study of the interaction between copyright and other forms of state intervention supporting the creative industries. Recall the original DCMS definition of creative industries, which placed the 'generation and exploitation' of IP at its core. Most definitions of creative industries, implicitly or explicitly, reinforce its centrality. For sociologists Lash and Urry (1993), for example, each of the creative industries has an irreducible core' concerned with 'the exchange of finance for rights in intellectual property' (p. 117). It is important to differentiate amongst the four types of intellectual property: patents, designs, trademarks and copyright. Each of the first three requires 'opting-in'; that is, the creator must apply for or register their piece of intellectual property. Only copyright is regarded as inhering in the act of creation, and it is the form of intellectual property which generates most debate in creative industries.

The centrality of IP 'generation and exploitation' in the creative industries might have been more straightforwardly obvious 20 years ago, but widespread and accelerating digitisation has meant that, while IP generation proceeds apace, the question of its exploitation has become more complicated.

The widening differences in approach to IP exploitation - particularly manifest in differing business models - are driving a wedge between established and new, digitised or digital-native, creative industries. On the one hand, the established sectors, which are often actually referred to as the copyright industries (WIPO), double down on the necessity of maintaining high-control copyright regimes, reinforced by technological advances in digital rights management and global advocacy for the maintenance and upgrade of legal enforcements of copyright. This is based on the well-established business model of the extraction of rents protected under copyright law. On the other hand, digital-native creative industries and workers increasingly are led to adopt variations of the software model and software-as-a-service where new business models, including value adding and freemium strategies, and models of the 'spreadability' of online content, including live appearances and community building, are as important to establish viability as rents/royalties derived through IP control.

The voices raised loudest at maintaining strong copyright protection, upgrading penalties for infringement - even sometimes strategically conflating piracy with arguments for fair use, remix practices, or open content licensing - are typically industry peak bodies, distributors and other intermediaries whose business is reliant on extraction of maximum value from copyrights in segmented territories around the world. Content creators and producers for whom this is their single or major business model (sales and licensing of rights to these intermediaries) are obviously invested in the continued stability of the system, but for many creators in the digital creative industries this is not their sole or major model, or it once was but now new models are needed.

Nicola Searle (2011; see also Searle and Brassell 2016; Townley et al. 2019) developed case studies in UK television, computer games and music, providing 
a snapshot of changing business models in three key creative sectors under the impact of digitisation (television and music) or natively digital (computer games):

\begin{abstract}
Surprisingly the research does not indicate that the case study firms felt that their business models developed and changed because of challenges to enforcement of IP. A common attitude was that piracy would always occur and should be minimised, but that it was more important to focus on creating new content. .. While IP is not perceived by the case study participants as an important influence on the structure of business models, it does play a number of roles in governing the implementation of business models. For example, out-of-copyright material can be a key resource for these business models. Overall, the evidence suggests that case study participants view IP as a secondary influence on their business models. (Searle 2011, p. 3)
\end{abstract}

One of the notable innovations that the 'platformisation' (Nieborg and Poell 2018) of cultural production has produced is a new global creative industry which has been called social media entertainment (Cunningham and Craig 2019). Millions of previously amateur creators have monetised their uploaded content on YouTube, Instagram or Twitch (with a parallel content universe on the Chinese platforms) without traditional copyright industry IP control. The platforms benefit from the 'safe harbour' provisions of the US Digital Millennium Copyright Act 1998, which protects them against copyright infringement liability, provided they responsively block access to alleged infringing material on receipt of infringement claims from a rights holder, and they do not control IP of content creators. A new business model -shared advertising revenue, typically split 55 (creator)/45 (platform) - replaced the traditional media model of owned or shared IP. Social media entertainment thrives on a 'co-opetitive' business culture dedicated to original content and rejects attempts to control content through trademarking. This is a clear example of the transfer of a software business model into the creative industries. This does not mean that traditional IP controls do not matter - the more successful the social media entertainer is, the more they will seek to negotiate traditional IP deals for merchandising and licensing. But the base of the business pyramid is not based on IP control, but on constant generation of very low cost, original content.

The disruptive effects of digitisation on the one hand, and 'fair use' and more efficient access to copyright materials for legitimate reuse on the other, have been twin drivers for many attempts in various jurisdictions to introduce reform and innovation into copyright policy. Legitimate concerns about crisis in the copyright industries from digitisation and the loss of traditional rents through piracy have overhung and inhibited many of these. The failure of the Digital Copyright Exchange initiative in the UK (Flew et al. 2013) and the signal failure of successive inquiries recommending the adoption of fair use and other reforms in Australia (Aufderheide et al. 2018) offer sobering reminders of the level of policy contestability in this domain.

Developing research agendas that can shed light on, and offer ways forward in, this fraught, contested area of policy are much needed. For a book like this, it is not 
appropriate that we adopt either what could be called a 'copyleftist' or 'copyrightist' position, but acknowledge the realities on both sides, as well as what has been attempted, and could be attempted, to address what is often debated in the most toxic and oppositional of terms. As creative industries face its increasingly digitised future, what is needed is not so much a position of 'weaker IP' ( $c f$. Montgomery and Potts 2008) but of much greater attention to business model innovation that puts IP control in its appropriate place amongst a suite of possible pathways for generation of value and sustainability.

\section{Is it important to differentiate economic, cultural and social rationales for and outcomes from creative industries, or should they be converged around the so-called 'triple bottom line'?}

The case that has been made for the creative industries in policy debates has most frequently been an economic one. Aggregate data has been generated that demonstrates the significant - and in many cases growing - contribution made by the creative industries to national economies, as demonstrated through metrics such as share of Gross National Product (GNP) or Gross Value Added (GVA), employment, and trade. As the Australian cultural economist David Throsby (2010) has observed, this has been part of a broader reshaping of debates internationally around the scope and purposes of cultural policy. As indicated in UNESCO reports from the 1970 and early 1980 s, cultural policy was at one time conceived of largely in terms of the contribution of the creative and performing arts to society and culture, and how this may be enhanced or improved.

By contrast, and in parallel with a broadening of the definition of culture to include the products of commercial cultural industries (Girard 1982; Garnham 1987), the case for cultural policy is increasingly couched in terms of its contribution to the creative economy, and the wider impact of the creative industries on other sectors of the economy (for example, Venturelli 2005; UNCTAD 2010). Throsby identified the logic behind this as essentially pragmatic, in helping to 'legitimise culture in the eyes of hard-headed economic policy-makers', and where 'cultural policy ... can be rescued from its primordial past and catapulted to the forefront of the modern forward-looking policy agenda, an essential component in any respectable economic policy-maker's development strategy' (Throsby 2010, p. 7).

The story that the data tells is generally a positive one. In the UK, where there is the longest history of data collection, the creative industries as originally defined constituted 5.3 per cent of GVA in 2016, and are as high as 14.2 per cent of GVA if other digital sectors, gambling, sport and tourism are included (DCMS 2018). The most recent study in Australia found that the creative and cultural sectors account for 6.4 per cent of the nation's GVA (BCAR 2018), and in China it has been found that the cultural and creative industries accounted for 4.1 per cent of the nation's gross domestic product (GDP) in 2017 (see Chapter 10). UNCTAD (2019) has 
found that trade in creative goods has more than doubled between 2002 and 2015 , and that creative services now account for 18.9 per cent of all trade in services, with the latter expected to grow significantly.

But the conflation of arts and culture with the creative industries, under the general rubric of all sectors being engaged with creativity as an economic input, and outputs being cultural in the anthropological sense of products that communicate symbolic meaning, comes at some cost. Rationales for public support for the creative and performing arts, for instance, have historically been based on arguments around their intrinsic cultural value, and the propensity for an undersupply of such valued cultural goods and services in the absence of public subsidy.

By contrast, public support for the creative industries has tended to be more akin to industry policy as applied to emerging sectors such as advanced manufacturing, in that it aims to promote innovation and enhance economic value, as measured by sales, employment and exports. In other words, the policy rationales for supporting the games industry or cutting-edge digital special effects and post-production are unlikely to be the same as those for supporting a regional dance company, a local artists' co-op or a chamber orchestra.

The DCMS originally combined these sectors on the basis of their common claims to generate copyrightable forms of intellectual property through the application of creativity. But, as we have just seen, this focus on copyright presents its own difficulties in the context of the growing digital economy. The revenues of the giant digital platform companies are derived not from copyright, but from the capacity to amass data from user interactions with cultural products which they explicitly do not own or control, which can then be on-sold to commercial advertisers. And as we have also seen, creative industries forming around these platforms operate with very different business, cultural and audience logics.

The challenges of addressing differing registers of value have been recognised by, among others, the cultural analyst John Holden (2009) and the Warwick Commission (2015) in its Report on the Future of Cultural Value. Holden proposed three registers of value that constitute a triangle:

1. Intrinsic value: the value that individuals and societies attach to cultural forms and practice in and of themselves, which is highly subjective and difficult to quantify.

2. Instrumental value: the value attached to cultural forms and practices in terms of their direct and tangible economic and social benefits, which is measurable, but should not be measured through purely economic metrics.

3. Institutional value: the value that cultural organisations contribute to - or subtract from - in their contribution to the public realm and the provision of public goods. This may include their contribution to public knowledge, social trust, a fair and equitable society, enabling civil society, addressing regional disparities, and other such measures of the public good. Holden suggests that 
this may be measurable through social impact metrics or what he terms Social Returns on Investment (Holden 2009, p. 454).

The Warwick Commission proposed that cultural and creative industries needed to be understood as an ecosystem where the connections between publicly funded culture, commercial culture, and non-market forms of cultural provision arise at the intersection of three forms of value:

1. Economic value, or the contribution to GVA, employment, exports, and 'spillover' or 'multiplier' effects.

2. Cultural value, or the role played in enriching the lives of citizens and communities, through enabling equitable access to cultural forms of the highest levels of artistic quality.

3. Social value, or the role in enabling participation in culture and realising creative capacities across all sections of the population, particularly underrepresented communities and groups.

This 'triple bottom line' draws upon the concept of integrating social, environmental and economic value that has developed in corporate social responsibility debates. But it has faced challenges in recent academic debates that seek to uncouple economic and cultural value. Banks (2018) has argued that 'creative growth' is not an appropriate cultural policy goal in light of inequalities arising from the distribution of social product, the adverse environmental consequences of capitalist economic growth, and the capacity to constrain cultural imaginaries through a one-dimensional focus upon profits and growth.

A forward research agenda for creative industries should not advocate economic growth per se as an end in itself. Following Piketty (2011), there is an intense global conversation about the distributional dimensions of capitalist growth, and the adverse political, social and indeed economic consequences of rising inequalities (cf. Wilkinson and Pickett 2009). The continuing - and perhaps growing - barriers to effective participation in the creative industries based upon class, gender, race and disability speak to the limits of 'business as usual', as do movements such as \#MeToo, Black Lives Matter, \#CommunicationSoWhite and others that are challenging the domination of these industries by white, middle-class males and the effects this has on equitable engagement with the arts, media and culture (Campbell et al. 2018; Saha 2018; Chakravartty et al. 2018). The quality of creative work is also a growing matter of concern, and the extent to which the logic of the 'gig economy' and workplace precarity is embedded in many fields of creative industries employment. There are also well-documented and longstanding limitations of conventional measures of economic activity such as GDP and GVA (Coyle 2015; Quiggin 2014), and these problems are reflected in the difficulties in capturing the value and significance of voluntary and non-market activities in cultural and creative industries statistics. On the other hand, as we will see, there is now a recognised capacity of creative industries, in the face of widespread concern about automation and the future of work, to generate jobs at rates often much higher than the general 
economy - jobs that even the critics agree can be meaningful and satisfying 'good work' (Banks 2018).

The multiplication of expectations seen in the triple bottom line is not unique to the creative industries. The higher education sector, for example, is now viewed in terms of its contribution to economic outcomes such as research and development, exports through the enrolment of international students, and its role in local and regional economies, as well as social value metrics such as equitable participation and inclusion of under-represented groups. These are goals that sit alongside its historic missions of advanced education and the creation of new knowledge. The field of stakeholder analysis (Flew and Lim 2019) points to the extent to which the performance of institutions - and particularly those where there is a public interest in their activities - is assessed across multiple criteria, and these tendencies are increasing rather than diminishing. In light of the growing crisis of trust in liberal democracies, corporations in sectors as diverse as banking and finance, mining, and the digital economy are expected to demonstrate their 'social licence to operate' (Hall and Jeanneret 2015).

The triple bottom line will continue to shape the relationship of creative industries to cultural policy for some time to come. One of the challenges of the creative industries is that they have tended not to collectively organise, meaning that the politics of cultural policy continue to be shaped disproportionately by the major arts and cultural organisations and arts funding bodies. At the same time, the 'participative turn' in cultural policy (Bonet and Négrier 2018) makes a return to an arts-centred, producer-focused cultural policy increasingly less likely, as the demands of the public as consumers, audiences, voters and creators of content particularly in online, digital spaces - are challenging supply-side framing of policy across a range of domains.

However, we must contemplate modifications and challenges to this fundamental given in cultural policy in any forward research agenda. An adherence to the triple bottom line - good for corporate responsibility publicity - can mask a lack of rigour in accounting for separate spheres of the economic, the social and the cultural. As Chapter 2 shows, only rigorous, policy-relevant economic and statistical research over time, together with advocacy that speaks with one voice, underpinned the recognition in the UK of the creative industries as a legitimate industry sector.

In a major break with past practice, UNCTAD' s (2018) major study, Creative Economy Outlook and Country Profiles, suggests:

In the creative economy policy space, it makes sense to separate the usually integrated 'cultural' and 'creative' policy. Currently many countries combine them. However, they serve two separate but related objectives, one commercial, and one cultural. As the creativedigital enmeshment expands, it will become increasingly difficult to avoid the separation of the two. (p. 18) 
The trends that lie behind this shift in UNCTAD's approach to mapping the global creative economy include the fact that creative services, especially design, are the drivers of creative industries growth, rather than cultural production. UNCTAD has recognised trends such as: the creative economy and the digital economy are increasingly intermeshed; small-scale audiovisual content (for example, YouTube) is booming; China is rapidly advancing in all areas; and the future of work agenda places imperatives for creative thinking in education.

Bakhshi and Cunningham (2016) earlier posed the question of whether cultural policy and creative industries policies should be uncoupled, which would allow for a clearer assessment of the cultural goals underpinning support for publiclysupported forms of arts and culture, and a clearer focus on the industrial policy goals and instruments underpinning support for sectors such as software, advertising, fashion and design.

What are needed, they argued, are official statistics which allow both cultural and creative activity to be taken full account of, acknowledging both the substantial overlap between the two areas of activity, as well as dealing as well as possible with the well-known challenges that underestimate the extent of cultural activity (for example, the extent of 'non-market output of market producers' and voluntary activity, which was captured in the Australian Bureau of Statistics' Satellite Account of Cultural and Creative Activity (ABS 2014)). It would also help to clarify that the cultural sector is supported by government mainly on cultural grounds, and that the creative industries are supported primarily because of their economic contribution. Both cultural and economic wellbeing are, they argued, of equal importance to government.

However, the development of such a research base for the economic case for the creative industries is very uneven globally. Few jurisdictions outside the UK have an established history of grappling with the definitional, policy and ultimately political issues raised by the creative industries as an economic category. Given twenty years of intensive policy-focused research in that jurisdiction, perhaps only in the UK can the case be made to distinguish clearly between the economic case for the creative industries and their cultural and social remit. The 'home' for creative industries remains, in most jurisdictions, cultural policy. But research can contribute to avoiding this being seen as a case of a Hobson's choice. More rigorous methods, such as those adopted by Geoffrey Crossick and Patrycja Kaszynska (2016) and The Warwick Commission (2015) for more forensic research into social and cultural value (Crossick and Patrycja Kaszynska identify accrual of benefit to the 'reflective individual', to civic agency and engagement, community vitality, arts-based learning in formal education, the value of volunteerism) are equally important.

Addressing the future of the triple bottom line is also becoming more important as the different economic dynamics of the cultural and the creative industries appear to be diverging more strongly. In a statistical analysis of the 2016 Australian Census of Population and Housing (DMRC 2018) creative employment in the creative 
economy is shown as growing at nearly twice the rate of the overall workforce. But when cultural production (including film, television and radio, music and performing arts, publishing and visual arts) and creative services (including advertising and marketing, architecture and design, and software and digital content) are separated out, three-quarters of jobs in the creative industries are in creative services, with the balance located in cultural production. Employment in the creative services sector is growing on average at nearly three times the rate of the overall workforce, and incomes in all sectors of the creative services sector are higher than the Australian average. The coherence of the creative industries as a sector is at issue.

There is a broader policy field that opens up when economic dynamism and jobs growth in the digital creative services industries is articulated to the future of work debate. This debate focuses on relative demand for skills and occupations, and new skills and occupations, into the near and medium-term future in the face of the impact of automation and the wider ramifications of the so-called 'fourth industrial revolution'. There is strong emerging evidence for the proposition that creative skills have a higher degree of resistance to automation (Bakhshi et al. 2017, 2018). Articulating the economic dynamism and jobs growth in the digital creative services industries to the future of work debate allows an exploratory sharpening of the distinction between the economic and the cultural while narrowing the gap between the economic and social. Particularly for younger people and the digitally literate, the social crisis of finding work that is both sustainable and meaningful is addressable through a focus on high-growth digital creative services industries. In this agenda, the cultural is able to return to a focus on what Holden calls intrinsic value.

\section{What research agendas can be developed from studying the embedding of creative industries into higher education?}

There is a strong symbiotic relationship between the creative industries and higher education. Universities and other higher education institutions provide critical enabling infrastructure for cultural activity. UNESCO has observed that:

education is the process by which culture is transmitted between generations ... [and] help[s] an individual to acquire skills to create and make cultural goods. It teaches people to appreciate the outcome of the consumption of cultural goods and services or the social benefit of a participation in a cultural activity. Education serves also for the transmission of intangible culture in a formal or informal system that forms the identity of a community. (UNESCO 2009, pp. 29-30)

Changes to higher education worldwide over the last 30 years have proceeded alongside the growth of the creative industries. Sectoral expansion associated with the turn to mass higher education, which saw former polytechnics, art colleges and technical institutes become universities, brought fields associated with the arts and creative practice, communication and related fields (for example, 
journalism), and design more explicitly within the university sector, challenging the hegemony of liberal arts and traditional humanities. The growth of user-pays higher education has promoted vocationalisation and a stronger focus upon jobrelated graduate attributes, which has required greater dialogue with industry generally. Outside of the STEM (Science, Technology, Engineering and Maths) disciplines, this has been associated with both a closer relationship with the creative industries as prospective employers, and the promotion of creativity as a core graduate attribute. The push towards what have variously been termed engagement and impact, knowledge exchange and 'third stream' activities, that sit alongside research and teaching as indicators of the contribution of universities to 'the world outside the "ivory tower"' (Moreton 2018, p. 328), has, as we have seen, resulted in greater awareness and closer relations, particularly when this aligns with support for local and regional economies (Comunian et al. 2014; see also Comunian, Chapter 3 in this volume).

The number of creative industries courses has grown significantly in the 2010s, particularly in the English-speaking world. There are now at least 20 creative industries courses offered by UK universities, mostly at the postgraduate level, meaning that creative industries courses are offered by 16 per cent of all UK universities (Flew 2019). In Australia, eight of the 40 public universities (20 per cent) offer creative industries courses at either undergraduate or postgraduate level. Many of the courses in the UK, and all but one of the courses in Australian universities, were established after 2010. Other substantial creative industries courses include the Creative Industries BA at Ryerson University in Canada, the Masters of Cultural and Creative Industries courses at the Communication University of China and Shanghai Jiao Tong University, the Creative Industries and Media Management course at the University of Porto in Portugal, and the doctoral training programme at the ICCA (Industries Culturelles e Création Artistique) at the University Paris13 in France. There is also considerable overlap between creative industries, media economics and media management programmes around the world.

Given the growth in creative industries courses in a period characterised by critics as one 'after the creative industries' (Banks and O'Connor 2009), there is surprisingly little known about the features of such courses. In their public descriptions, they tend to draw upon a similar script about the growth in the creative economy, the career opportunities for artists and creative entrepreneurs, and the scope to engage with industry and make use of leading-edge digital technologies, as seen with the three examples from course prospectuses below:

Launched in the fall of 2013, this innovative and interdisciplinary Bachelor of Arts degree programme studies the creative fields from the perspective of enterprise development and entrepreneurship. It is intended for students who envision an entrepreneurial career in media, design, entertainment or the visual and performing arts, and who are motivated to learn both how the creative process functions in these industries and how emerging technologies are reshaping them. (Ryerson School of Creative Industries, Ryerson University, Canada https://www.ryerson.ca/fcad/programs/creative-industries/) 
The creative economy is one of the most vibrant and culturally diverse industry sectors in the world. New audiences and new modes of delivery across all types of media make for a dynamic global cultural landscape. Producing ground-breaking work that supports the understanding, analysis and growth of this exciting and ever-changing creative sector is at the core of our research. We work closely with industry partners across all formats and around the globe to engage and innovate with real-life scenarios and projects. (Cultural and Creative Industries - University of Nottingham, UK, China and Malaysia, https://www. nottingham.ac.uk/clas/departments/culturalmediaandvisualstudies/research/researchthemes/cultural-and-creative-industries.aspx)

The creative industries create jobs and contribute to economic growth on a massive scale. As an indication of size, the creative industries employ more people globally than the car industries of Europe, Japan and the USA combined ... The School of Creative Industries plays a key role in the education, training and development of future leaders across all the arts and creative disciplines. Our partnerships and connections provide fantastic opportunities for staff and students to engage with industry, and strong career outcomes for students. (University of South Australia School of Creative Industries, Australia http://u. unisa.edu.au/Education-Arts-and-Social-Sciences/School-of-Creative-Industries/)

Whereas the marketing scripts look remarkably similar, the courses tend to be highly diverse in pedagogy and curriculum. Flew (2019) has observed that the units within these courses tend to cluster around four broad discipline areas:

1. Contextual courses: cultural and creative industries; cultural policy; creative work; cultural consumption; arts industries; entertainment industries.

2. Business courses: marketing, management; entrepreneurship.

3. Technology and design courses: interaction design; web design; video production.

4. Creative production courses: interactive storytelling; animation and games; creative and performing arts.

Courses often vary in terms of where they are offered, and how they combine these combinations of units. In some instances, creative industries courses have been about applying an enterprise focus to fine arts and media production courses, while in other instances they have replaced more traditional offerings in film, media and cultural studies. Some programmes are offered through business schools rather than arts faculties, while in some instances they have been explicitly designed to be jointly offered across arts and business, or arts and information technology.

The radical interdisciplinarity that is on display across these courses is both a strength and a weakness. It enables combinations of offerings that cut across disciplinary silos and more closely replicate the expectations of a changing jobs market. At the same time, the 'anything goes' approach, and the lack of scope for benchmarking between such courses to determine quality and graduate outcomes, mean that it is difficult to evaluate their distinctive contribution to higher education. In particular, as Bridgstock identifies in Chapter 7, the question of whether creative 
industries is 'fine arts plus', or the equivalent of the 'creative MBA', or something else new and different, remains difficult to untangle. Bridgstock points to considerable supply-side barriers to curriculum change that develops 'protean creative workers' who can navigate the fast-growing creative services sectors, including the disciplinary training of teaching staff, risk aversion about 'straying too far' from the cultural production disciplines, and student preference for acquiring practitioner skills for established fields, particularly in the creative arts.

As we have signalled earlier, research into the future of work, the marked and growing difference in job growth between cultural production and creative services, and the emergence of new industries such as social media entertainment, social media management and createch, may - should - push the education agenda forward. A research agenda that assists curriculum planners, pedagogic strategists, and teachers and lecturers to plan the most challenging and relevant education and training experiences will remain an essential and ongoing challenge.

\section{The chapters to come}

In keeping with the book's emphasis on research agendas responsive to, and even derived from, policy and industry concerns and experiences, the first two chapters are from leading policy and industry actors. John Newbigin is Chairman of Creative England. As Special Advisor to the Minister for Culture, Rt Hon. Chris Smith $\mathrm{MP}$, he was closely involved in developing the UK government's first policies for the creative industries in the 1990s. In a short, succinct essay, he covers almost all the bases that this book considers germane for a research agenda for creative industries. He emphasises the politically experimental, contingent nature of the 'uncharted territory' of 'raising the profile of an eclectic jumble of generally IP-based, culturally-rooted businesses that governments and banks had conspicuously failed to understand or take seriously as part of the economy'. In the 20 years since then, there has been intense debate, major statistical challenges, and wide take-up around the world. There are structural complexities: are creative industries typified by freelancers and just-in-time enterprises, or by some of the largest corporations in the world? Or both? Are the key policy actors and impacts to be found at the municipal level rather than the national? Regarding the future of work, Newbigin sees an increasingly important 'creative economy' developing alongside the 'machine economy'. This chapter is a superb primer for anyone wanting a hospitable introduction to what an industry and policy leader thinks is important for creative industries research.

Hasan Bakhshi is Executive Director, Creative Economy and Data Analytics, at Nesta. Awarded an MBE in 2015 for services to the creative industries, Hasan is a member of the UK government's Creative Industries Council and the Department for Digital, Culture, Media and Sport's Science Advisory Council. As someone who has, for many years, led research efforts and set research agendas with demonstrable policy impact, he lays out four key reasons why creative industries in the UK have 
come to be embraced at the highest policy level as a legitimate industrial sector. He calls these 'institutional factors for the growing recognition of the UK's creative industries'; most of them are the product of years of dedicated research directed toward policy agendas and impact. First, the creative industries are accepted by government as playing an integral role in the digitisation of the economy and vice versa. Second, policy-focused research has become much better at measuring the economic contributions of the creative industries, including understanding the significance of digital technology within it. Third, the UK Government has placed Research and Development (R\&D) at centre stage of its Industrial Strategy, and there has been initial success in making the case for public investment in creative industries R\&D. Fourth, the sector has organised effectively to represent its interests to government, with influential sector-wide bodies like the Creative Industries Council and, more recently, the Creative Industries Federation.

The next two chapters consider theoretical challenges in taking forward the creative industries research agenda. Roberta Comunian is Reader in Creative Economy at King's College London and Terry Flew is Professor of Communication and Creative Industries at Queensland University of Technology. Both spend some time surveying the current and recent trends in creative industries research. Both emphasise the broad range of disciplines in which this research is conducted: in the social sciences, geography, economics, public policy, urban studies and planning, sociology, business studies and management; in the humanities, media, communication, cultural studies and cultural policy. Both address the disjunctions that arise from a 'silo-ed' approach that only takes account of one, or a part of one, discipline's framework and assumptions.

For Comunian, this can be answered by embracing the potential of complexity theory to integrate knowledge at different (micro, miso, macro) scales. This would necessarily involve the deployment of different disciplinary knowledges; her chapter gives some engaging instances that combine qualitative and quantitative, as well as practice-based, research. Complexity theory also informs her argument for scaling-up creative industries research with larger and longitudinal studies.

Flew takes on one of the fundamental 'disjunctions' in creative industries research, that between regimes of cultural and economic value. While both social sciences (cultural economics) and the critical humanities (cultural studies) have sought to comprehend creative industries from within disciplinary assumptions, both have come up against limitations. In the case of cultural economics, the issue has been conservatism about its object of study, and a reluctance to engage with commercial popular culture and the digital. In the case of cultural studies, the association of quantitative methods with neoliberalism and an 'objectification' of culture has rendered the field opaque to policy-makers, as the measurement of culture appears as an inherently problematic exercise. Advances in the field will require a degree of replicability of methods as well as an openness to interdisciplinarity that must go beyond the current disciplinary stand-off. 
Research agendas for creative industries must always deal with these enduring disciplinary issues. But equally they must be looking to the future in terms both of new methods and new objects of study. John Davies has worked at the forefront of Nesta's development of research methods that have underpinned its policy impact in the UK. He itemises the data and methodological challenges posed for official measurement by the creative industries, and shows how these challenges have been addressed in three ways. First, official data sources and classifications are defined in a more sophisticated way. Second, new data sources created by the internet and digital technology are identified and mined. Third, digital methods, including machine learning techniques, analyse these new data sources better.

When it comes to new objects of study, the potential of distributed ledger technologies, or the blockchain, looms large on the horizon, and not only for creative industries. In their chapter on what they call Web3, Jason Potts and Ellie Rennie review how blockchain technology is currently being experimentally adopted into creative industries in order to improve transparency along supply chains, to lower costs of distribution by creating more direct platforms to connect artists and fans, and to improve handling of intellectual property and licensing arrangements, metadata, royalties and payments.

As flagged already in this Introduction, the creative industries research agenda is thin when it comes to education. As Ruth Bridgstock argues in her chapter, remarkably little has been done to explore the impact of the creative industries 'movement' on formal education and even less on the relation between creative industries coursework and pedagogy, and student outcomes. Given how much energy and time is expended by teachers and lecturers on this, their core business, this is a major area for a strengthened research agenda. Bridgstock offers a research agenda that addresses the relation between creative industries and the 21 st-century skills discourse; the cognitive dissonance created between creativity as a generic human attribute and specific creative industries skills sets; the gap between generally positive growth data for creative employment at the population level and the much more uneven graduate outcomes data; and what a creative industries curriculum actually looks like.

As also already flagged, the issue of intellectual property - copyright in particular - is a central issue that has the potential to divide creative industries practitioners, policy makers and researchers. Paul Stepan's chapter analyses the interaction between subsidies and copyright using the European film industry as a case in point. He argues that there is evidence to suggest that incentives deriving from copyright are completely or partially cancelled out by the incentives given by subsidies. This is a study from a welfare economic perspective of the potential for welfare losses as well as gains from copyright's interaction with other state support for copyrightbased creative industries.

The final set of chapters look at creative industries in spatial terms - as they are articulated in policy in specific national contexts. Stuart Cunningham and Adam 
Swift's chapter asks what distinctive variations on creative industries concepts and claims can be seen around the world, and what implications this may have for a comparative research agenda. There is, as we have seen, major country-by-country comparative research on creative industries performance, but this tends to be narrowly financial in nature. Cunningham and Swift's granular attention to political, social, cultural and economic dynamics of creative industries policy in a series of compact country case studies raises fundamental questions about how flexible creative industries policy settings can be, and what might be the irreducible elements that differentiate such policy from its near neighbours. The chapter's emphasis on the global South partially rebalances the book's de facto global North bias.

Flew, Ren and Wang's chapter on China's history of policy development around the creative industries shows that China now takes a sophisticated and strongly contemporised view of the potential of both cultural heritage and convergent digital 'createch'. Just as Chapter 2 makes much of the UK's placement of creative industries within core industry strategy, so this chapter is clear about the significance of the adoption, in China's 13th Five Year Plan (2016-2020), of the digital creative industries as one of the five 'strategic emerging industries'. Just as John Newbigin's opening chapter makes reference to the significance of China, so it is appropriate that we conclude with China's remarkable embrace of the potential of creative industries.

\section{References}

Aufderheide, P., Pappalardo, K., Suzor, N. and Stevens, J. (2018), 'Calculating the consequences of narrow Australian copyright exceptions: Measurable, hidden and incalculable costs to creators', Poetics, 69, 15-26.

Australian Bureau of Statistics (ABS) (2014), 'Australian national accounts: Cultural and creative activity satellite accounts, experimental, 2008-09', accessed 14 February 2019 at http://www.ausstats.abs. gov.au/ausstats/subscriber.nsf/o/EFFE2547EC51F5AACA257 C780ooC1B53/\$File/52710_2008-o9. pdf.

Bakhshi, H. and Cunningham, S. (2016), 'Cultural policy in the time of the creative industries', NESTA, accessed 14 February 2019 at https://media.nesta.org.uk/documents/cultural_policy_in_the_time_ of_the_creative_industries_pdf.

Bakhshi, H., Downing, J., Osborne, M. and Schneider, P. (2017), The Future of Skills: Employment in 203o. London: Pearson and NESTA, accessed at https://futureskills.pearson.com/research/assets/ pdfs/technical-report.pdf.

Bakhshi, H., Flew, T., Hearn, G. and Stewart, C. (2018), 'Nesta and the evolving policy agenda in the UK and Australia', Journal of Creative Industries and Cultural Studies, 2 (2), 30-45.

Banks, M. (2018), 'Creative economies of tomorrow? Limits to growth and the uncertain future', Cultural Trends, 27 (5), 367-80.

Banks, M. and O'Connor, J. (2009), 'After the creative industries', International Journal of Cultural Policy, 15 (4), 365-73.

Benner, M. (2018), The New Global Politics of Science: Knowledge, Markets and the State. Cheltenham, UK and Northampton, MA, USA: Edward Elgar Publishing.

Bureau of Communication and Arts Research (BCAR) (2018), Cultural and Creative Activity in Australia 2008-09 to 2016-17. Canberra: Department of Communication and the Arts. 
Bonet, L. and Négrier, E. (2018), 'The participative turn in cultural policy: Paradigms, models, contexts', Poetics, 66, 64-73.

Campbell, P., O’Brien, D. and Taylor, M. (2018), 'Cultural engagement and the economic performance of the cultural and creative industries: An occupational critique', Sociology, 1-21, published online before print 17 May 2017, doi: 10.1177/0038038518772737.

Caves, R. (200o), Creative Industries: Contracts between Art and Commerce. Cambridge, MA: Harvard University Press.

Chakravartty, P., Kuo, R., Grubbs, V. and McIlwain, C. (2018), '\#CommunicationSoWhite', Journal of Communication, 68 (2), 254-66.

Comunian, R., Taylor, C. and Smith, D. (2014), 'The role of universities in the regional creative economies of the UK: Hidden protagonists and the challenge of knowledge transfer', European Planning Studies, 22 (12), 2456-76.

Coyle, D. (2015), GDP: A Brief but Affectionate History. Princeton, NJ: Princeton University Press.

Crossick, G. and Kaszynska, P. (2016), Understanding the Value of Arts and Culture: The AHRC Cultural Value Project, Swindon: Arts and Humanities Research Council, accessed 14. February 2019 at http:// www.ahrc.ac.uk/documents/publications/cultural-value-project-final-report.

Cunningham, S. (1992), Framing Culture: Criticism and Policy in Australia. North Sydney: Allen and Unwin.

Cunningham, S. (2014), Hidden Innovation: Industry, Policy and the Creative Sector. Lanham, MD: Rowman and Littlefield/Lexington Books.

Cunningham, S. and Craig, D. (2019), Social Media Entertainment: The New Intersection of Hollywood and Silicon Valley. New York: NYU Press.

Davies, R. and Sigthorsson, G. (2013), Introducing the Creative Industries: From Theory to Practice. London: Sage.

Department for Culture, Media and Sport (DCMS) (1998), Creative Industries Mapping Document. London: DCMS.

Department for Culture, Media and Sport (DCMS) (2018), DCMS Sectors Economic Estimates. London: DCMS.

Digital Media Research Centre (DMRC, Queensland University of Technology) (2018), 'Australian cultural and creative activity: A population and hotspot analysis', accessed 14 February 2019 at https:// research.qut.edu.au/dmrc/projects/australian-cultural-creative-activity-a-population-hotspotanalysis.

Flew, T. (2012), 'Creative suburbia: Rethinking urban cultural policy - the Australian case', International Journal of Cultural Studies, 15 (3), 231-46.

Flew, T. (2019), 'From policy to curriculum: Drivers of the growth in creative industries courses in the UK and Australia', Creative Industries Journal, 12 (2), 167-84.

Flew, T. and Lim, T. (2019, forthcoming), 'Assessing policy - stakeholder analysis', in H. van den Bulck, M. Puppis, K. Donders and L. van Audenhove (eds), The Palgrave Handbook of Methods for Media Policy Research, Basingstoke: Palgrave Macmillan.

Flew, T., Suzor, N. and Liu, B. (2013), 'Copyrights and copyfights: Copyright law and the digital economy', International Journal of Technology Policy and Law, 1 (3), 297-315.

Florida, R. (2002), The Rise of the Creative Class. New York: Basic Books.

Florida, R. (2017), The New Urban Crisis: How Our Cities Are Increasing Inequality, Deepening Segregation, and Failing the Middle Class - and What We Can Do About It. New York: Basic Books.

Garnham, N. (1987), 'Public policy and the cultural industries', Cultural Studies, 1 (1), 23-37.

Girard, A. (1982), 'Cultural industries: A handicap of a new opportunity for cultural development?', in UNESCO, Cultural Industries: A Challenge for the Future, Paris: UNESCO, pp. 24-39.

Hall, N. and Jeanneret, T. (2015), 'Social licence to operate', Corporate Communications: An International Journal, 20 (2), 213-27. 
Holden, J. (2009), 'How we value arts and culture', Asia Pacific Journal of Arts and Cultural Management, $6(2), 447-56$.

Kimpeler, S. and Georgieff, P. (2008), 'The roles of creative industries in regional innovation and knowledge transfer: The case of Austria in measuring creativity', accessed 13 December 2018 at http:// ec.europa.eu/education/lifelong-learningpolicy/doc/creativity/report/austria.pdf.

Lash, S. and Urry, J. (1993), Economies of Signs and Space, London: Sage.

Lutz, J. and Karra, N. (2009), 'The UK designer fashion economy value relationships: Identifying barriers and creating opportunities for business growth', Creative Industries Journal, 2 (1), 117-19.

Markusen, A. (2014), 'Creative cities: A 10-year research agenda', Journal of Urban Affairs, 36 (2), 567-89.

Montgomery, L. and Potts, J. (2008), 'Does weaker copyright mean stronger creative industries? Some lessons from China', Creative Industries Journal, 1 (3), 245-61.

Moreton, S. (2018), 'Contributing to the creative economy imaginary: Universities and the creative sector', Cultural Trends, 27 (5), 327-38.

Müller, K., Rammer, C. and Trüby, J. (2008), 'The role of creative industries in industrial innovation', working paper No. 08-109, Centre for European Economic Research, Mannheim, accessed 14 February 2019 at http://ftp.zew.de/pub/zewdocs/dp/dpo8109.pdf.

Nieborg, D. and Poell, T. (2018), 'The platformization of cultural production: Theorizing the contingent cultural commodity', New Media and Society, 20 (11), 4275-92.

Oakley, K. and Ward, J. (2018), 'Creative economy, critical perspectives', Cultural Trends, 27 (5), 311-12.

Piketty, T. (2011), Capital in the 21st Century. Cambridge, MA: Harvard University Press.

Quiggin, J. (2014), 'National accounting and the digital economy', Economic Analysis and Policy, 44 (2), $136-42$.

Saha, A. (2018), Race and the Cultural Industries. Cambridge: Polity.

Searle, N. (2011), Changing Business Models in the Creative Industries: The Cases of Television, Computer Games and Music. London: Intellectual Property Office (UK), October.

Searle, N. and Brassell, M. (2016), Economic Approaches to Intellectual Property. Oxford: Oxford University Press.

Stoneman, P. (2011), Soft Innovation: Economics, Product Aesthetics and Creative Industries. Oxford: Oxford University Press.

Throsby, D. (2010), The Economics of Cultural Policy. Cambridge: Cambridge University Press.

Townley, B., Roscoe, P. and Searle, N. (2019), Creating Economy: Enterprise, Intellectual Property, and the Valuation of Goods. Oxford: Oxford University Press.

UNCTAD (2010), The Creative Economy Report 2010: A Feasible Development Option. Geneva: United Nations.

UNCTAD (2018), 'Creative economy outlook and country profiles: Trends in international trade in creative industries', Geneva: UNCTAD, accessed 14 February 2019 at https://unctad.org/en/ PublicationsLibrary/webditcted2016d5_en.pdf.

UNCTAD (2019), 'Global creative economy shows resilience, growth - report', accessed 14 February 2019 at https://unctad.org/en/pages/newsdetails.aspx?OriginalVersionID=1975.

UNESCO (2009), 'The 2009 UNESCO framework for cultural statistics', accessed 14 February 2019 at https://unesdoc.unesco.org/ark:/48223/pfoooo191061.

Venturelli, S. (2005), 'Culture and the creative economy in the information age', in J. Hartley (ed.), Creative Industries, Malden, MA: Blackwell, pp. 391-8.

Warwick Commission (2015), Enriching Britain: Culture, Creativity and Growth. Coventry: University of Warwick.

Westbury, M. (2015), Creating Cities. Melbourne: Niche Press.

Wilkinson, R. and Pickett, K. (2009), The Spirit Level: Why More Equal Societies Almost Always Do Better. London: Allen Lane. 